\title{
Pseudoscleroderma associated with POEMS syndrome
}

\section{Zespół rzekomotwardzinowy w przebiegu zespołu POEMS}

Kalina Wysocka-Dubielecka', Andrzej Bizoń', Katarzyna Głogowska', Dorota Mączyńska-Karcz', Katarzyna Łoza', Kazimierz Kalbarczyk', Oskar Janeczek², Marek Braszkiewicz ${ }^{3}$

\author{
'Department of Adult Dermatology, Miedzyleski Specialist Hospital, Warsaw, Poland \\ 2Department of Neurology, Międzyleski Specialist Hospital, Warsaw, Poland

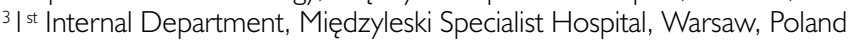 \\ 'Oddział Dermatologii Dorosłych, Międzyleski Szpital Specjalistyczny, Warszawa, Polska \\ ${ }^{2}$ Oddział Neurologiczny, Międzyleski Szpital Specjalistyczny, Warszawa, Polska \\ ${ }^{3}$ Oddział I Wewnętrzny, Międzyleski Szpital Specjalistyczny, Warszawa, Polska
}

Dermatol Rev/Przegl Dermatol 2019, 106, 529-537

DOI: https://doi.org/l0.51 |4/dr.2019.9000।

\section{CORRESPONDING AUTHOR/ ADRES DO KORESPONDENCJI: \\ Kalina Wysocka-Dubielecka \\ Oddział Dermatologii Dorosłych \\ Międzyleski Szpital \\ Specjalistyczny \\ ul. Bursztynowa 2 \\ 04-749 Warszawa, Polska}

tel.: +48224735292

e-mail: kalina.wysocka@gmail.com

\begin{abstract}
POEMS syndrome is a rare paraneoplastic disorder associated with plasma cell dyscrasia. The acronym stands for coexisting polyneuropathy, organomegaly, endocrinopathy, monoclonal gammopathy and skin changes. Other relevant features of the syndrome are papilledema, sclerotic bone lesions, Castleman's disease, thrombocytosis, weight loss and increased vascular endothelial growth factor levels. The diagnostic criteria for POEMS are as follows: major criteria: polyneuropathy, monoclonal plasma cell dyscrasia; minor criteria: sclerotic bone lesions, Castleman's disease, organomegaly, endocrinopathies, edemas, skin changes, papilledema. To make a diagnosis, 2 major criteria and $1 \mathrm{mi}$ nor criterion are required. We present a patient with pseudoscleroderma, polyneuropathy, hypothyroidism, monoclonal gammopathy, edemas and weight loss, who was diagnosed with POEMS syndrome as a result of interdisciplinary cooperation.
\end{abstract}

\section{STRESZCZENIE}

Zespół POEMS jest rzadkim schorzeniem paraneoplastycznym związanym z dyskrazją plazmocytów. Akronim POEMS odzwierciedla współwystępowanie polineuropatii, organomegalii, endokrynopatii, gammapatii monoklonalnej oraz zmian skórnych. Inne istotne cechy tego zespołu to obrzęk tarczy nerwu wzrokowego, ogniska osteosklerotyczne $\mathrm{w}$ kościach, choroba Castlemana, trombocytoza, utrata masy ciała oraz podwyższone stężenie czynnika wzrostu śródbłonka naczyniowego. Kryteria diagnostyczne zespołu POEMS dzielą się na duże i małe. Do kryteriów dużych zalicza się polineuropatię monoklonalną i dyskrazję plazmocytów, a do kryteriów małych - sklerotyczne zmiany kości, chorobę Castlemana, organomegalię, endokrynopatie, obrzęki, zmiany skórne oraz obrzęk tarczy nerwu wzrokowego. Do rozpoznania konieczne jest stwierdzenie 2 kryteriów dużych i 1 kryterium małego. Przedstawiamy przypadek pacjentki ze zmianami rzekomotwardzinowymi, polineuropatią, niedoczynnością tarczycy, gammapatią monoklonalną, obrzękami i utratą masy ciała, u której zdiagnozowano zespół POEMS dzięki współpracy interdyscyplinarnej. 
Key words: hypothyroidism, polyneuropathy, monoclonal gammopathy, pseudoscleroderma, POEMS syndrome.

Słowa kluczowe: niedoczynność tarczycy, polineuropatia, gammapatia monoklonalna, stwardnienie rzekomotwardzinowe, zespół POEMS.

\section{INTRODUCTION}

POEMS syndrome is a rare paraneoplastic disorder associated with plasma cell dyscrasia. The acronym stands for coexisting polyneuropathy, organomegaly, endocrinopathy, monoclonal gammopathy and skin changes. Other relevant features of the syndrome are: papilledema, sclerotic bone lesions, Castleman's disease, thrombocytosis, weight loss and increased vascular endothelial growth factor (VEGF) levels $[1,2]$.

\section{OBJECTIVE}

To present a case report of a patient with pseudoscleroderma associated with POEMS syndrome.

\section{CASE REPORT}

A 67-year-old woman presented with thickening and induration of the skin of upper and lower extremities associated with muscle weakening, edema of extremities and generalized pain of muscles and joints 9 months before admission to the Dermatology Department. Additionally, there were significant fluctuations of thyroid-stimulating hormone (TSH) level (despite regular levothyroxine supplementation under supervision of an endocrinologist) and weight loss of $11 \mathrm{~kg}$. Five months later the patient noted joint stiffness, difficulties in swallowing and opening her mouth, paroxysmal paleness and pain of fingers, and exercise-induced dyspnea. Two months before admission to our department the patient was hospitalized at the Department of Internal Medicine, where tested antibodies ANA2 and anti-cyclic citrullinated peptide (anti-CCP) and activity of aldolase were negative. The patient had previously had hypothyroidism after radioiodine therapy of GravesBasedow disease, ischemic heart disease (required 2 coronarographies), paroxysmal atrial fibrillation, arterial hypertension, hypercholesterolemia, lumbosacral spine discopathy, and surgical treatment for cataract, and there was rheumatoid arthritis in the mother.

Physical examination revealed severe edema and induration of the skin of lower extremities (fig. 1), sli-

\section{WPROWADZENIE}

Zespół POEMS jest rzadkim schorzeniem paraneoplastycznym związanym z dyskrazją plazmocytów. Akronim POEMS określa współwystępowanie polineuropatii, organomegalii, endokrynopatii, gammapatii monoklonalnej oraz zmian skórnych (polyneuropathy, organomegaly, endocrinopathy, monoclonal gammopathy and skin changes). Inne istotne cechy tego zespołu obejmują obrzęk tarczy nerwu wzrokowego, ogniska osteosklerotyczne w kościach, chorobę Castlemana, trombocytozę, utratę masy ciała oraz podwyższony poziom czynnika wzrostu śródbłonka naczyniowego (vascular endothelial growth factor - VEGF) [1, 2].

\section{CEL}

Przedstawienie przypadku pacjentki ze zmianami rzekomotwardzinowymi w przebiegu zespołu POEMS.

\section{OPIS PRZYPADKU}

U 67-letniej kobiety wystąpiły zgrubienie i stwardnienia w obrębie skóry kończyn górnych i dolnych z towarzyszącym osłabieniem siły mięśniowej i obrzękami kończyn oraz uogólnionymi bólami mięśni i stawów, które pojawiły się 9 miesięcy przed hospitalizacją w oddziale dermatologicznym. Ponadto od tego czasu obserwowano znaczne zmiany stężenia hormonu tyreotropowego (TSH), pomimo przyjmowania lewotyroksyny pod stałą kontrolą endokrynologiczną oraz redukcję masy ciała o 11 kg. Pięć miesięcy później pojawiła się sztywność stawów, trudności w połykaniu i otwieraniu jamy ustnej, napadowe blednięcie i ból palców rąk, duszność nasilająca się po wysiłku. Dwa miesiące przed hospitalizacją na oddziale dermatologii chora była $\mathrm{z}$ tego powodu diagnozowana na oddziale chorób wewnętrznych, gdzie wykonano oznaczenia przeciwciał ANA 2 i przeciw cyklicznemu peptydowi cytrulinowemu (anty-CCP) oraz aktywności aldolazy - wyniki były ujemne. W wywiadzie chora podawała niedoczynność tarczycy po terapii radiojodem choroby Gravesa-Basedowa, chorobę niedokrwienną serca (wymagającą 2-krotnie koronarografii), napadowe migotanie przedsionków, nadciśnienie tętnicze, hipercholesterolemię, dyskopatię odcinka lędźwiowo-krzyżowego 
ght skin thickness and induration on the forearms, sclerotic hands edema with fingers flexion contracture (fig. 2), stiffness of the hips, knees, elbows and small joints of the hands, muscles weakness of upper and lower extremities, and face telangiectasias. Laboratory tests revealed normocytic anemia, periodical leucopenia, proteinuria, reduced total protein level, elevated $\alpha 1$ - and $\alpha 2$-globulin levels in protein electrophoresis, accelerated erythrocyte sedimentation rate (ESR), C-reactive protein (CRP), TSH, uric acid, D-dimer (table 1). ANA and phospholipid antibody tests were negative. No significant abnormalities were found in capillaroscopy and spirometry. Contrast X-ray of the esophagus excluded functional disorders. Imaging examinations (computed tomography - CT) scan of the chest, the abdomen and the lesser pelvis) did not identify any neoplastic foci. No inflammatory or neoplastic lesions were found during physical and gynecological examination. Despite levothyroxine dose adjustment according to endocrinologist recommendations the TSH level did not normalize. Histopathology examination of a skin sample from the right thigh showed atrophic, smoothened epithelium with evident (mostly follicular) keratinization, connective tissue edema with collagen degeneration, minimal round cell infiltrates around blood vessels and preserved skin appendages (fig. 3). An orcein stain visualized evident reduction of elastic fiber number, especially in the upper dermal layers (fig. 4). A periodic acid-Schiff (PAS) stain did not show the presence of PAS-positive substance (fig. 5). Histopathology was not characteristic - it presented features of both scleroderma and lichen sclerosus.

Implemented treatment with prednisone at the initial dose of $50 \mathrm{mg} /$ day $(0.65 \mathrm{mg} / \mathrm{kg} \mathrm{bw})$ led to gradual improvement. During follow-up an attempt to reduce the prednisone dose below $40 \mathrm{mg} /$ day $(0.5 \mathrm{mg} / \mathrm{kg} \mathrm{bw})$ led to exacerbation of symptoms. Three months later repeated ANA and aldolase tests

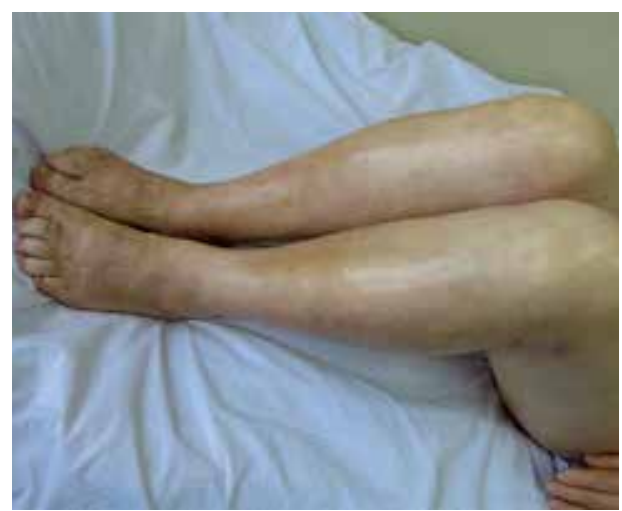

Figure I. Edema and induration of the skin of lower extremities Rycina I. Obrzęk i stwardnienia skóry kończyn dolnych kręgosłupa, chirurgiczne leczenie zaćmy oraz w wywiadzie reumatoidalne zapalenie stawów u matki.

W badaniu przedmiotowym stwierdzono nasilony obrzęk i stwardnienia w obrębie kończyn dolnych (ryc. 1), nieznaczne stwardnienia przedramion, stwardniały obrzęk rąk z rozwijającym się przykurczem zgięciowym palców (ryc. 2), sztywność stawów biodrowych, kolanowych, łokciowych, drobnych stawów rąk, osłabienie siły mięśniowej kończyn górnych i dolnych oraz teleangiektazje na twarzy. W badaniach laboratoryjnych obserwowano niedokrwistość normocytarną, okresowo leukopenię, białkomocz, w elektroforezie białek zmniejszone stężenie białka całkowitego i albumin oraz podwyższone stężenie a1- i $\alpha 2$-globulin, przyspieszony odczyn Biernackiego (OB), podwyższone stężenie białka C-reaktywnego (CRP), TSH, kwasu moczowego, D-dimeru (tab. 1). Wykonano oznaczenie przeciwciał ANA i fosfolipidowych - były ujemne. W kapilaroskopii i spirometrii nie stwierdzono istotnych nieprawidłowości. Badanie rentgenowskie (RTG) przełyku z kontrastem wykluczyło zaburzenia czynnościowe. W badaniach obrazowych (tomografia komputerowa klatki piersiowej, brzucha i miednicy mniejszej) nie stwierdzono ognisk nowotworowych. W badaniu internistycznym i ginekologicznym również nie wykazano ognisk zapalnych ani rozrostowych. Pomimo modyfikacji dawki lewotyroksyny zgodnie z zaleceniami endokrynologa stężenie TSH nie uległo normalizacji. W badaniu histopatologicznym wycinka skóry z uda prawego widoczny był zanikowy, wygładzony naskórek z wyraźnym rogowaceniem, zwłaszcza mieszkowym oraz obrzęk podścieliska ze zwyrodnieniem kolagenu, minimalne nacieki okrągłokomórkowe wokół naczyń i zachowanych przydatków (ryc. 3). Barwienie orceiną uwidoczniło wyraźne zmniejszenie liczby włókien sprężystych, zwłaszcza w górnych partiach skóry właściwej (ryc. 4). Barwienie PAS (periodic acid-Schiff) nie wykazało obecności substancji PAS-dodatniej (ryc. 5). Obraz histologiczny był niecharakterystyczny, miał cechy zarówno twardziny, jak i liszaja twardzinowego.

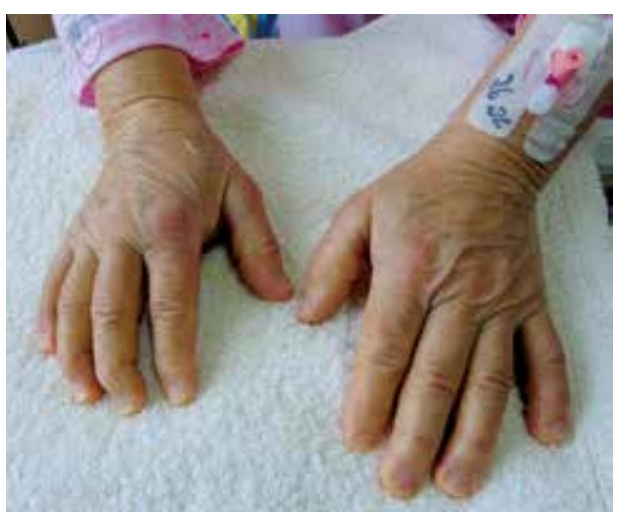

Figure 2. Sclerotic hands edema with fingers flexion contracture Rycina 2. Obrzęk stwardniały i przykurcz zgięciowy palców rąk 


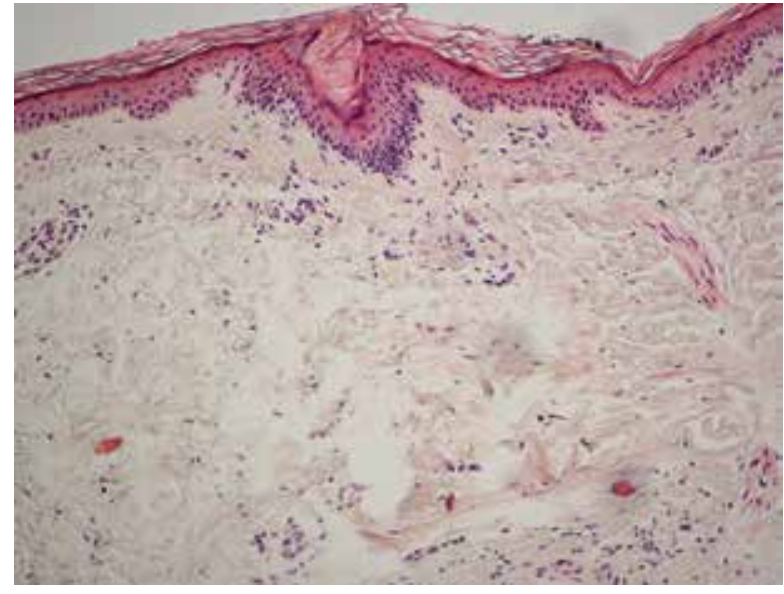

Figure 3. Atrophic, smoothened epithelium with evident (mostly follicular) keratinization, connective tissue edema with collagen degeneration, minimal round cell infiltrates around blood vessels and preserved skin appendages

Rycina 3. Zanikowy, wygładzony naskórek z wyraźnym rogowaceniem (głównie mieszkowym), obrzęk podścieliska ze zwyrodnieniem kolagenu, minimalne, okrągłokomórkowe nacieki wokół naczyń i zachowanych przydatków skóry

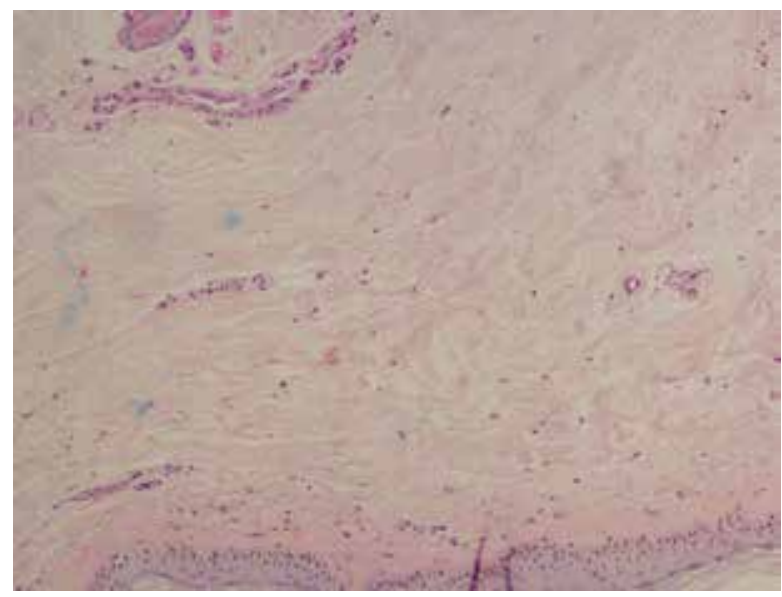

were negative. A histopathology examination of a deep tissue sample from a thigh excluded eosinophilic fasciitis. Laboratory tests showed elevated CRP and ESR levels, and leucopenia with eosinophilia (table 1). Because of anemia blood transfusion was necessary. Despite levothyroxine dose adjustment high TSH levels were observed (table 1). The consulting neurologist raised a suspicion of polyneuropathy due to POEMS. Treatment with prednisone at a dose of 60 $\mathrm{mg} /$ day $(0.8 \mathrm{mg} / \mathrm{kg} \mathrm{bw})$ was implemented.

Performed magnetic resonance imaging (MRI) of the lumbosacral spine revealed arthritis and multilevel discopathy. An electromyography (EMG) examination was indicative for sensory-motor axonal type polyneuropathy. Bone marrow cytology showed elevated plasma cell percentage $(26 \%)$, which could be indicative for plasma cell myeloma.

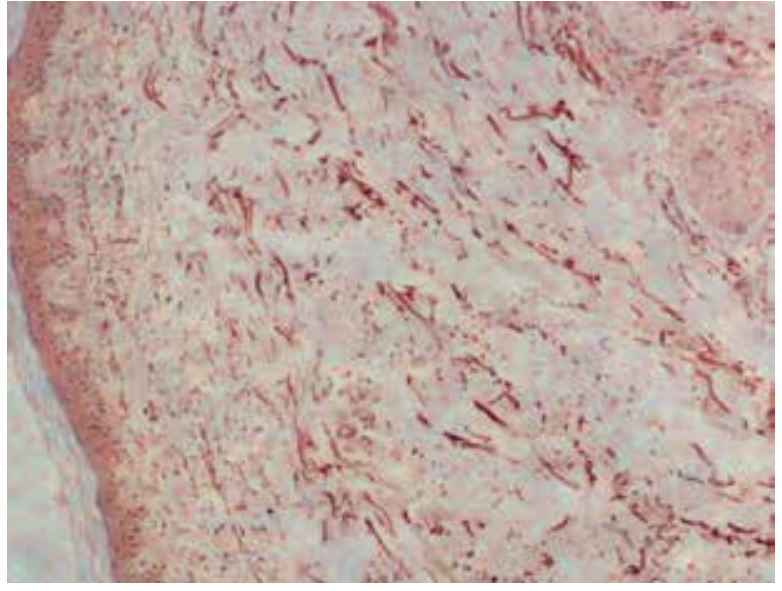

Figure 4. Orcein staining - evident reduction of elastic fiber number, especially in the upper dermal layers

Rycina 4. Barwienie orceiną - wyraźne zmniejszenie liczby włókien sprężystych, zwłaszcza w górnych partiach skóry właściwej

Figure 5. PAS (periodic acid-Schiff) staining - no presence of PASpositive substance

Rycina 5. Barwienie PAS - nie uwidoczniono substancji PAS-dodatniej

W leczeniu zastosowano prednizon w początkowej dawce $50 \mathrm{mg} /$ dobę $(0,65 \mathrm{mg} / \mathrm{kg}$ m.c.), uzyskując stopniową poprawę. Przy próbie redukcji dawki prednizonu poniżej $40 \mathrm{mg} /$ dobę $(0,5 \mathrm{mg} / \mathrm{kg}$ m.c.) obserwowano nasilenie dolegliwości. Trzy miesiące później ponownie oznaczono przeciwciała przeciwjądrowe i aktywność aldolazy - wyniki były prawidłowe. Pobrano głęboki wycinek z uda do badania histopatologicznego, w którym wykluczono eozynofilowe zapalenie powięzi. W badaniach laboratoryjnych utrzymywał się podwyższony poziom CRP, OB, leukopenia z eozynofilią (tab. 1). Z powodu niedokrwistości chora wymagała przetoczenia krwi. Nadal obserwowano wysoki poziom TSH (tab. 1), pomimo modyfikacji dawki lewotyroksyny. Po konsultacji neurologicznej wysunięto podejrzenie polineuropatii w przebiegu zespołu POEMS. Do leczenia ponownie włączono prednizon w dawce $60 \mathrm{mg} /$ dobę $(0,8 \mathrm{mg} / \mathrm{kg}$ m.c.). 
Table I. Results of selected laboratory tests

Tabela I. Wyniki wybranych badań laboratoryjnych

\begin{tabular}{|c|c|c|c|c|c|c|}
\hline \multirow[t]{2}{*}{ Parameter/Parametr } & \multicolumn{6}{|c|}{ Day/Dzień } \\
\hline & 22.02 & 05.03 & 15.05 & 27.05 & 26.06 & 05.09 \\
\hline \multicolumn{7}{|l|}{ Blood smear/Rozmaz krwi: } \\
\hline WBC (4-10 G/l) & 3.1 & 6.3 & 3.8 & 9.1 & 7.7 & 7.55 \\
\hline $\mathrm{RBC}(4.2-5.4 \mathrm{~T} / \mathrm{l})$ & 2.87 & 3.21 & 2.94 & 3.48 & 3.75 & 3.93 \\
\hline $\mathrm{HGB}(7.4-9.9 \mathrm{mmol} / \mathrm{l})$ & 5.2 & 5.6 & 5.5 & 6.6 & 7.2 & 12.1 \\
\hline $\mathrm{HT}(0.370-0.500 \mathrm{I} / \mathrm{l})$ & 0.266 & 0.289 & 0.278 & 0.332 & 0.348 & 0.377 \\
\hline NEUT (2.0-7.2 G/l) & 1.6 & 5.1 & 1.9 & & 6.3 & 4.72 \\
\hline LYMPH (I.2-3.2 G/l) & 1.8 & 1.1 & 1.5 & & 2.1 & 2.31 \\
\hline $\mathrm{MO}(0.3-0.7 \mathrm{G} / \mathrm{l})$ & 0.2 & 0.1 & 0.2 & & 0.4 & 0.45 \\
\hline $\mathrm{EO}(0.03-0.27 \mathrm{G} / \mathrm{l})$ & 0.19 & 0.0 & 0.11 & & 0.02 & 0.05 \\
\hline $\mathrm{BA}(0.0-0.1 \mathrm{G} / \mathrm{l})$ & 0.0 & 0.0 & 0.0 & & 0.0 & 0.02 \\
\hline \multicolumn{7}{|c|}{ Manual CBC/Morfologia krwi z rozmazem manualnym: } \\
\hline$S(45.0-65.0 \%)$ & 38.0 & 78.0 & 51.0 & & & \\
\hline $\mathrm{EO}(0.0-5.0 \%)$ & 3.0 & & 6.0 & & & \\
\hline $\mathrm{BA}(0.0-1.0 \%)$ & 1.0 & & 1.0 & & & \\
\hline LYMPH (20.0-45.0\%) & 50.0 & $\begin{array}{c}18.0 \\
\text { Atypic/Atypowe } \\
1.0\end{array}$ & 37.0 & & & \\
\hline $\mathrm{MO}(2.0-8.0 \%)$ & 8.0 & 3.0 & 5.0 & & & \\
\hline Total protein/Białko całkowite (66-83 g/l) & & 49 & 56 & & 55 & 62.8 \\
\hline \multicolumn{7}{|l|}{ Protein electrophoresis/Proteinogram: } \\
\hline Albumin/Albumina (59.8-72.4\%) & & 58.6 & 62.0 & & 65.2 & 53.2 \\
\hline$\alpha \mid(\mid .0-3.2 \%)$ & & 5.4 & 4.6 & & 3.9 & 2.9 \\
\hline$\alpha 2(7.4-12.6 \%)$ & & 14.7 & 13.3 & & 14.2 & 18.7 \\
\hline$\beta(7.5-12.9 \%)$ & & 11.8 & 11.3 & & 11.5 & 16.7 \\
\hline$\gamma(8.0-15.8 \%)$ & & 9.5 & 8.8 & & 5.2 & 8.5 \\
\hline ESR/OB (I-20 mm) & 53 & 51 & 60 & 15 & 28 & \\
\hline $\operatorname{CRP}(<5.0 \mathrm{mg} / \mathrm{l})$ & 26.9 & 12.6 & 8.8 & 1.7 & 9.0 & \\
\hline $\mathrm{TSH}(0.550-4.780 \mu \mathrm{l} \mathrm{U} / \mathrm{ml})$ & 11.598 & 12.893 & 8.033 & 6.614 & 2.808 & \\
\hline Uric acid/Kwas moczowy ( I 54-357 $\mu \mathrm{mol} / \mathrm{l})$ & 416.7 & & 352.2 & & 308.2 & 386.6 \\
\hline D-dimer/D-dimery $(<500$ ng/ml) & 6331.0 & & 24435.0 & 2064.0 & & \\
\hline $\mathrm{Ca}(2.2-2.55 \mathrm{mmol} / \mathrm{l})$ & & & & & 2.5 & 2.81 \\
\hline
\end{tabular}

WBC - white blood cells, $L Y M P H$ - lymphocytes, S - segmented neutrophils, RBC - red blood cells, MO - monocytes, ESR - erythrocyte sedimentation rate, HGB - hemoglobin, EO - eosinophils, CRP - C-reactive protein, HT - hematocrit, BA - basophils, TSH - thyroid-stimulating hormone, NEUT - neutrophils, $\mathrm{CBC}$ - complete blood count, Ca-calcium.

WBC - knwinki białe, LYMPH - limfocyty, S - neutrofile segmentowane, RBC - knwinki czerwone, MO - monocyty, OB - odczyn Biernackiego, HGB - hemoglobina, EO - eozynofile, CRP - białko C-reaktywne, HT - hematokryt, BA - bazofile, TSH - hormon tyreotropowy, NEUT - neutrofile, CBC - morfologia krwi, Ca-wapń.

Because of a suspicion of POEMS syndrome the patient was hospitalized in the Institute of Hematology and Transplantology. A skeleton X-ray showed bone atrophy in the spine and the pelvis, spotted bone atrophy in the humerus and femur bones and a fracture of the right femur neck. A myelogram revealed normal, cellular-rich bone marrow with
$\mathrm{W}$ rezonansie magnetycznym (magnetic resonance imaging - MRI) kręgosłupa lędźwiowo-krzyżowego stwierdzono zmiany zwyrodnieniowe i wielopoziomową dyskopatię. W badaniu elektromiograficznym (EMG) wykazano polineuropatię czuciowo-ruchową typu aksonalnego. W badaniu cytologicznym szpiku stwierdzono zwiększony odsetek plazmocytów 
plasma cells and proplasmacytes consisting of $17 \%$ of lymphatic system. Bone marrow trepanobiopsy showed reduced cellularity of the bone marrow, and $1 / 3$ of the bone marrow was highly hypoplastic (cellularity $<5 \%$ ) with plasma cell infiltrates comprising $20-25 \%$ of all bone marrow cells. Blood immunofixation showed monoclonal protein corresponding to light immunoglobulin chain $\lambda$ type. No $\operatorname{IgD}$ or $\operatorname{IgE}$ monoclonal proteins were found. Urine immunofixation showed monoclonal protein composite of free light immunoglobulin chains $\lambda$ type and minimal albumin fraction. Biochemistry tests revealed hypercalcemia. Previously observed abnormalities were maintained (table 1). The patient was qualified for cytostatic therapy with the CTD regimen (cyclophosphamide, thalidomide, dexamethasone).

\section{DISCUSSION}

POEMS syndrome was first described by Crow in 1956 [3]. The peak incidence occurs at the age of $50-60$. The 5-year survival is approximately $60 \%$ and greater than that of multiple myeloma [4] Clinical features that affect the prognosis are: clubbing, edemas, effusions and ascites. Death is often caused by cachexia, heart failure, respiratory failure, brain stroke or myocardial infarction [5].

The diagnostic criteria for POEMS syndrome are as follows [1, 2]: major criteria: polyneuropathy, monoclonal plasma cell dyscrasia; minor criteria: sclerotic bone lesions, Castleman's disease, organomegaly, endocrinopathies, edemas, skin changes, papilledema.

To make a diagnosis, 2 major criteria and 1 minor criterion are required.

The predominant feature of the syndrome is acute, progressive sensorimotor polyneuropathy caused by demyelination and connected with plasma cell dyscrasia $[1,2,6,7]$. In patients with POEMS syndrome, monoclonal (M) protein of the IgG or IgA class, mostly composed of $\lambda$ light chains or only light chains, is observed $[2,7,8]$. The $M$ protein is primarily found in blood (85-90\%) and rarely in urine [9]. A useful test for monoclonal protein and light chain detection is immunofixation $[1,2]$. Bone marrow is normal in about one third of the cases. In other cases, different levels of increased plasma cell count are found. When a radiographic assessment reveals focal bone lesions, bone marrow testing often confirms plasmocytoma, i.e. localized plasma cell hyperplasia $[9,10]$. Most patients with POEMS syndrome demonstrate various endocrine disorders [11]. The most common conditions are hypogonadism, hypothyroidism, diabetes mellitus, adrenal insufficiency, hyperprolactinemia and hypoparathyroidism [12]. The mechanism of endocrine disorder development is unclear [13]. Or-
(26\%), co mogło wskazywać na szpiczaka plazmocytowego.

Z powodu podejrzenia zespołu POEMS chorą hospitalizowano w Instytucie Hematologii i Transfuzjologii. W RTG kośćca stwierdzono zaniki kostne kręgosłupa, miednicy, plamisty zanik kostny w kościach ramiennych i udowych oraz złamanie szyjki kości udowej prawej. W mielogramie: szpik prawidłowo bogatokomórkowy, plazmocyty i proplazmocyty stanowiły 17\% układu chłonnego. W trepanobiopsji stwierdzono: szpik o obniżonej komórkowości, 1/3 szpiku wybitnie hipoplastyczna (komórkowość < 5\%), z naciekami z komórek plazmatycznych stanowiących 20-25\% wszystkich komórek szpiku. W badaniu immunofiksacyjnym krwi wykryto białko monoklonalne odpowiadające lekkiemu łańcuchowi immunoglobulinowemu typu $\lambda$, nie znaleziono białka monoklonalnego klasy IgD i IgE. W badaniu immunofiksacyjnym moczu stwierdzono białko monoklonalne złożone z wolnych lekkich łańcuchów immunoglobulinowych typu $\lambda$ i śladową frakcję albumin. W badaniach biochemicznych krwi pojawiła się hiperkalcemia, nadal utrzymywały się dotychczasowe nieprawidłowości (tab. 1). Chorą zakwalifikowano do leczenia cytostatycznego według schematu CTD (cyklofosfamid, talidomid, deksametazon).

\section{OMÓWIENIE}

Zespół POEMS został po raz pierwszy opisany przez Crowe'a w 1956 roku [3]. Szczyt występowania choroby przypada na 50.-60. rok życia. Pięcioletnie przeżycie wynosi około $60 \%$ i jest ono większe niż w przypadku szpiczaka mnogiego [4]. Cechy kliniczne pogarszające rokowanie to występowanie pałeczkowatych palców, obrzęków i wysięków w jamach ciała. Przyczyną zgonu zwykle jest wyniszczenie, niewydolność krążeniowo-oddechowa, udar mózgu lub zawał serca [5].

Kryteria diagnostyczne zespołu POEMS są następujące [1, 2]: kryteria wielkie: polineuropatia monoklonalna, dyskrazja plazmocytów; kryteria małe: sklerotyczne zmiany kości, choroba Castlemana, organomegalia, endokrynopatie, obrzęki, zmiany skórne, obrzęk tarczy nerwu wzrokowego.

Do rozpoznania konieczne jest stwierdzenie 2 kryteriów wielkich i 1 kryterium małego.

Najważniejszą cechą zespołu jest ostra, postępująca polineuropatia czuciowo-ruchowa spowodowana demielinizacją i związana z dyskrazją komórek plazmatycznych [1, 2, 6, 7]. U chorych z zespołem POEMS stwierdza się obecność białka monoklonalnego M klasy IgG lub IgA, składającego się najczęściej z łańcuchów lekkich $\lambda$ lub tylko łańcuchów lekkich $[2,7,8]$. Białko M występuje głównie we krwi (85-90\%), rzadko w moczu [9]. W detekcji białka monokonalnego i łańcuchów lekkich pomocny jest test immunofiksacji $[1,2]$. Szpik bywa prawidłowy w około $1 / 3$ przypadków. U pozo- 
ganomegaly is most commonly manifested by hepatomegaly and splenomegaly but also by cardiomegaly or lymphadenopathy, particularly with co-existing Castleman's disease [14]. Skin changes observed in POEMS syndrome are progressive, generalized hyperpigmentation, vast sclerodermoid changes, hypertrichosis of the extremities, hyperhidrosis, clubbed distal phalanges and multiple glomeruloid hemangiomas [15-18]. Facial lipoatrophy [19] and, very rarely, calcification are also reported [20]. In extremely rare cases, violet coloring of the skin over plasmocytoma lesions, accompanied by local lymphadenopathy, is observed [21]. Other symptoms of POEMS syndrome include weight loss, thrombocytosis, polycythemia and hyperhidrosis. Pulmonary hypertension, chronic obstructive pulmonary disease, thrombotic diathesis, arthralgia, cardiomyopathy, pyrexia, low levels of vitamin $\mathrm{B}_{12}$, diarrhea and ischemic events may also occur [5].

Methods of treatment include radiotherapy, chemotherapy and glucocorticosteroid therapy [1, 2, 22]. When the osteosclerotic lesions are solitary or restricted to a limited area, there is an indication for radiotherapy [1, 2]. Widespread lesions require systemic treatment. Chemotherapy includes an alkylating agent alone or in combination with glucocorticosteroids. Another method is autologous hematopoietic stem cell transplantation, preceded by high-dose chemotherapy [1, 2, 22-24]. New treatments are thalidomide and lenalidomide. Their mechanism of action is VEGF and tumor necrosis factor inhibition [1, 2, $23,25,26]$.

\section{CONCLUSIONS}

Proper diagnosis of POEMS syndrome can be difficult but a thorough medical history and physical examination combined with appropriate testing (particularly bone radiography [27, 28], and a careful analysis of the biopsy specimen [29]) may help distinguish the syndrome from other conditions, such as chronic inflammatory demyelinating polyneuropathy, monoclonal gammopathy of undetermined significance, neuropathy or amyloid neuropathy with immunoglobulin light chains [30]. Such patients demand interdisciplinary medical care.

\section{CONFLICT OF INTEREST}

The authors declare no conflict of interest. stałych chorych częściej stwierdza się różnego stopnia wzrost odsetka plazmocytów. W przypadku wykrycia radiologicznych zmian ogniskowych $\mathrm{w}$ kościach badanie szpiku często potwierdza rozpoznanie plazmocytoma, $\mathrm{tj}$. ogniskowego rozrostu komórek plazmoidalnych $[9,10]$. Większość pacjentów z zespołem POEMS cierpi na różnorodne zaburzenia endokrynologiczne [11]. Najczęściej występujące schorzenia to: hipogonadyzm, niedoczynność tarczycy, cukrzyca, niewydolność nadnerczy, hiperprolaktynemia, niedoczynność przytarczyc [12]. Mechanizm rozwoju zaburzeń endokrynnych w tym zespole jest nieznany [13]. Organomegalia najczęściej objawia się hepatomegalią, splenomegalią, a także kardiomegalią lub powiększeniem węzłów chłonnych, zwłaszcza przy współistniejącej chorobie Castlemana [14]. Zmiany skórne występujące w zespole POEMS to: postępujące uogólnione przebarwienia skóry, rozległe stwardnienia skóry, nadmierne owłosienie kończyn, wzmożona potliwość, pałeczkowate poszerzenie dystalnych paliczków i liczne rozsiane naczyniaki morfologicznie przypominające kłębuszki nerkowe [15-18]. Opisywana jest także lipoatrofia twarzy [19] oraz bardzo rzadko kalcyfilaksja [20]. Jeszcze rzadziej można obserwować fiołkowe zabarwienie skóry nad zmianami o typie plazmocytoma, z towarzyszącym powiększeniem regionalnych węzłów chłonnych [21]. Inne objawy występujące w zespole POEMS to: ubytek masy ciała, trombocytoza, policytemia, wzmożona potliwość. Mogą również współwystępować nadciśnienie płucne, przewlekła obturacyjna choroba płuc, skaza płytkowa, artralgia, kardiomiopatia, gorączka, zmniejszone stężenie witaminy $\mathrm{B}_{12}$, biegunka i incydenty niedokrwienne [5].

Leczenie zespołu obejmuje radioterapię, chemioterapię i steroidoterapię [1, 2, 22]. Pojedyncze lub występujące na ograniczonym obszarze ogniska osteosklerotyczne są wskazaniem do radioterapii [1, 2]. W przypadku zmian rozsianych włącza się leczenie ogólne. W chemioterapii wykorzystywane są związki alkilujące w monoterapii lub w skojarzeniu z glikokortykosteroidami. Stosowana jest również autologiczna transplantacja hematopoetycznych komórek macierzystych, poprzedzona intensywną chemioterapią [1, 2, 22-24]. Nowe leki używane w terapii to talidomid i lenalidomid, których mechanizm działania polega na hamowaniu VEGF oraz TNF [1, 22, 23, $25,26]$.

\section{WNIOSKI}

Prawidłowe rozpoznanie zespołu POEMS może przysparzać trudności, jednak dokładnie przeprowadzony wywiad i badanie przedmiotowe w połączeniu z odpowiednimi badaniami diagnostycznymi (zwłaszcza rentgenowskim badaniem kośćca [27, 28] i dokładną analizą badania histopatologicznego [29]) ułatwiają różnicowanie tego zespołu z innymi 
jednostkami chorobowymi, takimi jak przewlekła zapalna polineuropatia demielinizacyjna, gammapatia monoklonalna o nieokreślonym znaczeniu, neuropatia czy amyloidowa neuroptia z łańcuchami lekkimi immunoglobulin [30]. Pacjenci z zespołem POEMS wymagają interdyscyplinarnej opieki medycznej.

\section{KONFLIKT INTERESÓW}

Autorzy nie zgłaszają konfliktu interesów.

\section{References}

\section{Piśmiennictwo}

1. Dispenzieri A., Morra E., Weber D.: POEMS syndrome. Am Soc Hematol Educ Program 2005, 1, 360-367.

2. Dispenzieri A., Kyle R., Lacy M., Rajkumar S., Therneau T., Larson D., et al.: POEMS syndrome, definitions and long-term outcome. Blood 2003, 101, 2496-2506.

3. Stankowski-Drengler T., Gertz M., Katzmann J., Lacy M., Kumar S., Leung N., et al.: Serum immunoglobulin free light chain measurements and heavy chain isotype usage provide insight into disease biology in patients with POEMS syndrome. Am J Hematol 2010, 85, 431-434.

4. Miralles G., O'Fallon J., Talley N.: Plasma-cell dyscrasia with polyneuropathy. The spectrum of POEMS syndrome. N Engl J Med 1992, 327, 1919-1923.

5. Drac H.: Polineuropatie w gammapatiach monoklonalnych. Pol Przegl Neurol 2009, 5, 80-87.

6. Soubrier M., Dubost J., Sauvezie B.: POEMS syndrome: a study of 25 cases and review of the literature. Am J Med 1994, 97, 543-553.

7. Laugeny A., Bouillot S., Vital C., Ferrer X., Larrieu J., Vital A.: POEMS syndrome (or Crow-Fukase syndrome). Rev Neurol 2004, 160, 285-295.

8. Zhu W., Wang Y., Zeng X., Wang Q., Shen T.: A clinical analysis of 32 cases of POEMS syndrome. Zhongua Nei Ke Zhi 2006, 45, 108111.

9. Nakanishi T., Sobue I., Toyokura Y., Nishitani H., Kuroiwa Y., Satoyoshi E.: The Crow-Fukase syndrome: a study of 102 cases in Japan. Neuorology 1984, 34, 712-720.

10. Bitter M., Komaiko W., Franklin W.: Giant lymph node hyperplasia with osteoblastic bone lesions and the POEMS (Takatsuki's) syndrome. Cancer 1985, 56, 188-194.

11. Dispenzieri A.: POEMS syndrome. Blood Rev 2007, 21, 285-299.

12. Dispenzieri A., Kyle R., Lacy M., Rajkumar S., Therneau T., Larson D., et al.: POEMS syndrome: definitions and long-term outcome. Blood 2003, 101, 2496-2506.

13. Lizis-Kolus K., Kowalska A., Nowakowska-Domagała M.: Opis przypadku chorej z zespołem POEMS i towarzyszącymi endokrynopatiami. Endokrynol Pol 2007, 58, 238-243.

14. Nowak K., Krzemień S., Mendrek W., Hołowiecki J.: Białaczkowa postać zespołu POEMS - opis przypadku. Acta Haematol Pol $2003,3,375-382$.

15. Kanitakis J., Roger H., Soubier M., Dubost J., Chouvet B., Souteyrand P.: Cutaneus angiomas in POEMS syndrome. An ultrastructural and innunohistochemical study. Arch Dermatol 1988, 124, 695-698.

16. Judge M., McGibbon D., Thompson R.: Angioendotheliomatosis associated with Castleman's lymphoma and POEMS syndrome. Clin Exp Dermatol 1993, 18, 360-362.

17. Chan J., Fletcher C., Hicklin G.: Glomeruloid hemangioma: a distinctive cutaneous lesion of multicentric Castleman's disease associated with POEMS's syndrome. Am J Surg Pathol 1990, 14, 1036-1046.

18. Rogoziński T., Drac H., Janik P.: POEMS - wielonarządowy zespół objawów z zajęciem nerwów obwodowych i skóry. Przegl Dermatol 2001, 88, 519-524.

19. Barete S., Mouawad R., Choquet S., Viala K., Leblond V., Musset L., et al.: Skin manifestations and vascular endothelial growth factor levels in POEMS syndrome: impact of autologous hematopoietic stem cell transplantation. Arch Dermatol 2010, 146, 615-623.

20. Yoshikawa M., Uhara H., Arakura F., Procaccio P., Perosa F.: Calciphylaxis in POEMS syndrome: a case treated with etidronate. Acta Derm Venereol 2011, 91, 98-99.

21. Lipsker D., Rondeau M., Massard G., Grosshans E.: The AESOP (adenopathy and extensive skin patch overlying a plasmacytoma) syndrome: report of 4 cases of a new syndrome revealing POEMS (polyneuropathy, organomegaly, endocrinopathy, monoclonal protein, and skin changes) syndrome at a curable stage. Medicine 2003, 82, 51-59.

22. Koijma H., Kotsuoka Y., Katsura Y., Suzuki S., Suzukawa K., Hasegawa Y., et al.: Succesful treatment of a patient with POEMS syndrome by tandem high-dose chemotherapy with autologous CD34+ purged stem cells rescue. Int J Hematol 2006, 84, 182-185.

23. Dispenzieri A., Gertz M.: Treatment options for POEMS syndrome. Expert Opin Pharmacother 2005, 6, 945-953.

24. Kuwabara S., Misawa S., Kanai K., Kikkawa Y., Nishimura M., Nakaseko C., et al.: Autologous peripheral blood cell transplantation for POEMS syndrome. Neurology 2006, 66, 105-107. 
25. Kim S., Lee S., Ryo H., Lee K., Hyun M., Bae S.: Thalidomide for POEMS syndrome. ANN Hemat 2006, 85, 545-546.

26. Sinisalo M., Hietaharju A., Sauranen J., Wirta O.: Thalidomide in POEMS syndrome: case report. Am J Hematol 2004, 76, 66-68.

27. Alberti M., Martinez-Yelamos S., Fernandez A., Vidaller A., Narvaez J., Cano L., et al.: 18F-FDG PET/CT in the evaluation of POEMS syndrome. Eur J Radiol 2010, 76, 180-182.

28. Marinho F.S., Pirmez R., Nogueira T., Cuzzi T., Sodré C.T., Ramos-e-Silva M.: Cutaneous manifestations in POEMS syndrome: case report and review. Case Rep Dermatol 2015, 7, 61-69.

29. Dao L., Hanson C., Dispenzieri A., Morice W., Kurtin P., Hoyer J.: Bone marrow histopathology in POEMS syndrome: a distinctive combination of plasma cell, lymphoid and myeloid findings in 87 patients. Blood 2011, 117, 6438-6444.

30. Dispenzieri A.: How I treat POEMS syndrome. Blood 2012, 119, 5650-5658.

Received: 5.07 .2019

Accepted: 21.07.2019

Otrzymano: 5.07.2019 r.

Zaakceptowano: 21.07.2019 r.

How to cite this article

Wysocka-Dubielecka K., Bizoń A., Głogowska K., Mączyńska-Karcz D., Łoza K., Kalbarczyk K., Janeczek O., Braszkiewicz M.: Pseudoscleroderma associated with POEMS syndrome. Dermatol Rev/Przegl Dermatol 2019, 106, 529-537.

DOI: https://doi.org/10.5114/dr.2019.90001. 